\title{
Molecular Identity of Periglomerular and Short Axon Cells
}

\author{
Emi Kiyokage, ${ }^{1}$ Yu-Zhen Pan, ${ }^{1}$ Zuoyi Shao, ${ }^{1}$ Kazuto Kobayashi, ${ }^{3}$ Gabor Szabo, ${ }^{2}$ Yuchio Yanagawa, ${ }^{4}$ Kunihiko Obata, \\ Hideyuki Okano, ${ }^{6}$ Kazunori Toida, ${ }^{5}$ Adam C. Puche, ${ }^{1}$ and Michael T. Shipley ${ }^{1}$ \\ ${ }^{1}$ Department of Anatomy and Neurobiology, University of Maryland, School of Medicine, Baltimore, Maryland 21201, ${ }^{2}$ Department of Gene Technology and \\ Developmental Neurobiology, Institute of Experimental Medicine, H-1450 Budapest, Hungary, ${ }^{3}$ Department of Molecular Genetics, Institute of Biomedical \\ Sciences, Fukushima Medical University School of Medicine, Fukushima 960-1295, Japan, ${ }^{4}$ National Institute for Physiological Sciences, Okazaki, Aichi, \\ 444 - 8585, Japan, ${ }^{5}$ Department of Anatomy, Kawasaki Medical School, Matsushima, Kurashiki 701-0192, Japan, and ${ }^{6}$ Department of Physiology, Keio \\ University School of Medicine, Tokyo 160-8582, Japan
}

Within glomeruli, the initial sites of synaptic integration in the olfactory pathway, olfactory sensory axons terminate on dendrites of projection and juxtaglomerular (JG) neurons. JG cells form at least two major circuits: the classic intraglomerular circuit consisting of external tufted (ET) and periglomerular (PG) cells and an interglomerular circuit comprised of the long-range connections of short axon (SA) cells. We examined the projections and the synaptic inputs of identified JG cell chemotypes using mice expressing green fluorescent protein (GFP) driven by the promoter for glutamic acid decarboxylase (GAD) $65 \mathrm{kDa}, 67 \mathrm{kDa}$, or tyrosine hydroxylase (TH). Virtually all (97\%) TH + cells are also GAD67+ and are thus DAergic-GABAergic neurons. Using a combination of retrograde tracing, whole-cell patch-clamp recording, and single-cell three-dimensional reconstruction, we show that different JG cell chemotypes contribute to distinct microcircuits within or between glomeruli. GAD65 + GABAergic PG cells ramify principally within one glomerulus and participate in uniglomerular circuits. DAergic-GABAergic cells have extensive interglomerular projections. DAergic-GABAergic SA cells comprise two subgroups. One subpopulation contacts 5-12 glomeruli and is referred to as "oligoglomerular." Approximately one-third of these oligoglomerular DAergic SA cells receive direct olfactory nerve $(\mathrm{ON})$ synaptic input, and the remaining two-thirds receive input via a disynaptic $\mathrm{ON} \rightarrow \mathrm{ET} \rightarrow \mathrm{SA}$ circuit. The second population of DAergic-GABAergic SA cells also disynaptic ON input and connect tens to hundreds of glomeruli in an extensive "polyglomerular" network. Although DAergic JG cells have traditionally been considered PG cells, their interglomerular connections argue that they are more appropriately classified as SA cells.

\section{Introduction}

Olfactory sensory neurons (OSNs) project to the olfactory bulb (OB), where they synapse on the dendrites of second-order output neurons, mitral/tufted cells. This input is modulated by local juxtaglomerular (JG) neurons comprising three basic morphological classes, or morphotypes: external tufted (ET), short axon (SA), and periglomerular (PG). Each of the cell types is described below.

ET cells have a single dendrite that arborizes extensively in one glomerulus, an axon projecting out of the glomerular layer, and generate spontaneous bursts of action potentials (Pinching and Powell, 1971; Macrides and Schneider, 1982; Hayar et al., 2004a). A second population of tufted cells, superficial tufted (ST) cells, some of which express cholecystokinin, link lateral and medial glomeruli innervated by the same receptor type and form the intrabulbar associational circuit (Schoenfeld et al., 1985; Liu and

\footnotetext{
Received July 17, 2009; revised Nov. 23, 2009; accepted Nov. 25, 2009.

This work was supported by National Institutes of Health-National Institute on Deafness and Other Communication Disorders Grant R01 DC0056760.

E. Kiyokage's present address: Department of Anatomy, Kawasaki Medical School, Matsushima, Kurashiki 7010192, Japan.

Correspondence should be addressed to Dr. Michael T. Shipley, Department of Anatomy and Neurobiology, School of Medicine, University of Maryland, 20 Penn Street, Baltimore, MD 21201. E-mail: mshipley@ umaryland.edu.

DOI:10.1523/JNEUROSCI.3497-09.2010

Copyright $\odot 2010$ the authors $\quad 0270-6474 / 10 / 301185-12 \$ 15.00 / 0$
}

Shipley, 1994; Lodovichi et al., 2003). ST cells, whose somata are positioned at the glomerular/external plexiform layer (EPL) boundary, have an apical dendrite that ramifies in one glomerulus. However, unlike ET cells, ST cells have one or more lateral dendrites coursing in the superficial EPL.

SA cells have infrequently branched dendrites contacting 2-4 glomeruli (Price and Powell, 1970; Pinching and Powell, 1971) and long thin interglomerular processes that ramify over distances up to $1 \mathrm{~mm}$ (Aungst et al., 2003). PG cells are the largest subpopulation exhibiting short dendrites that are generally thought to ramify in a single glomerulus (Pinching and Powell, 1971).

Once considered a uniform population of GABAergic interneurons, it is now recognized that JG cells are neurochemically heterogeneous (Ribak et al., 1977; Kosaka et al., 1998; Toida et al., 1998, 2000; Briñón et al., 1999; Parrish-Aungst et al., 2007). Most are GABAergic expressing either glutamic acid decarboxylase (GAD) $65 \mathrm{kDa}, 67 \mathrm{kDa}$, or both (Parrish-Aungst et al., 2007). Despite having similar modes of action, these enzymes are the product of separate genes, are differentially expressed by various neuron subpopulations, and are differentially distributed within cells (Erlander et al., 1991). Approximately 10\% of JG cells express tyrosine hydroxylase $(\mathrm{TH})$, the rate-limiting enzyme for the biosynthesis of dopamine (DA) (Halász et al., 1977, 1985; McLean and Shipley, 1988; Toida et al., 2000; Parrish-Aungst et al., 2007). These DAergic cells also express GABA (Kosaka et al., 
1985, 1988, 1995; Gall et al., 1987; Baker et al., 1988); 97\% coexpress GAD67 and $\sim 18 \%$ coexpress GAD65 (Parrish-Aungst et al., 2007). Additional partially overlapping JG cell chemotypes express other neurochemical/neurotransmitter markers, e.g., calretinin, calbindin, neurocalcin (for review, see Shipley et al., 2004).

Glomerular microcircuits are also diverse. The glomerular neuropil is partitioned into domains containing predominantly olfactory nerve (ON) axodendritic synapses and domains containing mainly dendrodendritic synapses (Chao et al., 1997; Kasowski et al., 1999). Calbindin PG cells receive almost no ON input, but make extensive dendrodendritic synapses (Toida et al., 1998). Conversely, DAergic JG neurons receive ON as well as dendrodendritic synapses (Toida et al., 2000). The GAD65+ PG cell chemotype comprises two subpopulations based on $\mathrm{ON}$ input: approximately one-third receive direct monosynaptic input (ON driven), and approximately two-thirds receive their most effective $\mathrm{ON}$ input via a disynaptic $\mathrm{ON} \rightarrow \mathrm{ET} \rightarrow \mathrm{PG}$ circuit (ET driven) (Shao et al., 2009). Here we report that DAergic neurons show the same patterns of synaptic input (ON driven and ET driven). Thus, at the population level, a given cell's chemotype does not predict its general pattern of synaptic inputs.

How does chemotype relate to morphotype? Essentially all $\mathrm{TH}+$ cells express GAD67; however, DAergic-GABAergic neurons represent $\angle 20 \%$ of all GABAergic glomerular neurons and $\sim 10 \%$ of all JG cells (Parrish-Aungst et al., 2007); in contrast, $<7 \%$ of GAD $65+$ cells express TH. Here we show that GAD65+ PG cells ramify primarily within a single glomerulus and have a uniglomerular morphotype. In contrast, $\mathrm{TH}+$ cells extend processes into multiple glomeruli. Thus, the neurochemical identity of JG cells predicts the spatial extent of the glomerular networks in which they participate.

\section{Materials and Methods}

Animals. Glutamic acid decarboxylase $65 \mathrm{kDa}$ (GAD65), $67 \mathrm{kDa}$ (GAD67), and TH transgenic mice express green fluorescent protein (GFP) under the control of their respective gene promoters. The generation of GAD65-GFP, GAD67-GFP, and TH-GFP transgenic mice has been reported previously (Sawamoto et al., 2001; Matsushita et al., 2002; Tamamaki et al., 2003; López-Bendito et al., 2004; Kaneko et al., 2008). Briefly, GAD65-GFP transgenic mice contain a random insertion of a 6.5 $\mathrm{kb}$ segment of the GAD65 gene driving GFP expression in GABAergic neurons in most brain regions. This construct includes $5.5 \mathrm{~kb}$ of $5^{\prime}$ upstream sequence, the first two exons, and a portion of the third exon with corresponding introns. Mice are from the line GAD65_3e/gfp5.5 $\# 30$ on a genetic background of C57BL/6 with an F1 backcross to B6CBAF1/J wild-type mice yielding mice heterozygous for the transgene. TH-GFP mice were generated using a $9.0 \mathrm{~kb} 5$ '-flanking region of the rat $\mathrm{TH}$ gene, the second intron of the rabbit $\beta$-globin gene, green fluorescent protein, and polyadenylation signals of the rabbit $\beta$-globin and simian virus 40 early genes (on a genetic background of C57BL/6J $\times \mathrm{DBA} / 2 \mathrm{~J}$ backcrossed to C57BL/6J yielding mice heterozygous for the transgene). Since these constructs were randomly inserted, the endogenous gene loci are unaffected. GAD67-GFP transgenic mice were generated by homologous recombination of green fluorescent protein and a loxP-flanked neomycin-resistance cassette into the GAD67 loci. The line of mice used in this study had the neomycin cassette recombined out (GAD67-GFP $\Delta$ neo on a CBA/C57BL/6J genetic background backcrossed to C57BL/6J wild type yielding mice heterozygous for the transgene and heterozygous for the endogenous GAD67 gene). All experimental procedures were performed in accordance with the University of Maryland Institutional Animal Care and Use Committee and National Institute of Health guidelines.

Fluorogold and DiI tracer injections. GAD67-GFP transgenic mice (6-8 weeks old) were anesthetized with sodium pentobarbital (Nembutal, 50 $\mathrm{mg} / \mathrm{kg}$ ), positioned in a stereotaxic apparatus, and Fluorogold (1\% in saline; FG, hydroxystilbamidine, Invitrogen) iontophoretically injected by square-pulse positive current $(5 \mu \mathrm{A}, 7 \mathrm{~s}$ duty cycle, tip diameter $8 \mu \mathrm{m}$, 5-8 $\mathrm{min}$ ) into the medial glomerular layer (GL) of right OB. To avoid leaving an injection track through the glomerular layer of this bulb, the injection pipette was positioned $1.0 \mathrm{~mm}$ lateral over the left $\mathrm{OB}$, angled at $45^{\circ}$, and inserted $1.45-1.60 \mathrm{~mm}$ through the left $\mathrm{OB}$ into the right $\mathrm{OB}$ nerve layer, ending in the right $\mathrm{OB}$ glomerular layer (stereotaxic injection site target; $4.3-4.5 \mathrm{~mm}$ bregma, $0.12 \mathrm{~mm}$ lateral, 1.07 deep). To verify the GL position of the pipette during insertion, field potential and singleunit electrophysiology signals were recorded from the pipette and insertion stopped upon detecting the characteristic respiratory linked activity in the GL. Following $48 \mathrm{~h}$ survival, mice were anesthetized and transcardially perfused with $0.9 \%$ sodium chloride followed by $4 \%$ paraformaldehyde in $0.1 \mathrm{M}$ phosphate buffer (PFA, pH 7.4). The brains were serially sectioned (40 $\mu \mathrm{m}$, horizontal plane). Sections were sequentially incubated in $1 \%$ bovine serum albumin in $0.1 \mathrm{~m}$ PBS (BSA-PBS) for $1 \mathrm{~h}$, a mixture of rabbit polyclonal anti-FG antibody (1:30,000, Millipore Bioscience Research Reagents AB153) and mouse monoclonal anti-TH antibody $\left(1: 20,000\right.$, ImmunoStar 22941) for $48 \mathrm{~h}$ at $22^{\circ} \mathrm{C}$, rinsed several times in PBS, incubated in a mixture of $\mathrm{Cy} 3$-conjugated donkey antirabbit IgG (1:500, Jackson ImmunoResearch) and Cy5-conjugated donkey anti-mouse IgG (1:500, Jackson ImmunoResearch) for $2 \mathrm{~h}$, rinsed several times in PBS, and counterstained with $50 \mathrm{~nm} 4^{\prime}$,6-diamidino-2phenylindole (DAPI) in PBS for $30 \mathrm{~min}$. Sections were mounted in a DABCO-based antifade mounting medium.

The analysis of FG-labeled cell distribution in the GL was performed on image series captured with an Olympus FluoView 500 confocal microscope in both an anterior-posterior and a dorsal-ventral axis, centered on the injection site in each animal. In the anterior-posterior plane, the glomerular layer was divided into contiguous $100 \mu \mathrm{m}$ regions photographed in both anterior and posterior directions. In the dorsal-ventral plane, images were captured in every third section dorsal and ventral to the injection site (image region $210 \times 210 \mu \mathrm{m}$ ). Confocal images were captured through the full $40 \mu \mathrm{m}$ thickness of slice in $1 \mu \mathrm{m}$ optical steps resulting in an image stack of $\sim 40$ images. FG-positive somata were identified and colocalization with TH or GAD67-GFP determined for each cell. Standard cell counting exclusion criteria were used (Russ and Dehoff, 1998), any cell contacting the top of the section (first image in the stack), the lower, or right, edge of a of a counting grid was excluded. Any cell contacting the bottom of the section (last image in the stack), the upper, or left edge of the grid was included. Cells within the EPL, defined as occurring when the cell was surrounded by dense granule cell dendrite GFP labeling present in the EPL neuropil of this line of mice, were also excluded.

DiI labeling was performed in four TH-GFP transgenic mice and three GAD67-GFP mice. Animals were anesthetized and transcardially perfused with $4 \%$ PFA. The brains were removed and a single glomerulus in each main olfactory bulb injected iontophoretically with DiI $(1 \mathrm{mg} / \mathrm{ml}$ in ethanol, 2-3 $\mu \mathrm{A}$ square-pulse current, tip diameter $1.5 \mu \mathrm{m}, 30-60 \mathrm{~s}$ ) (Aungst et al., 2003). The brains were incubated at $30^{\circ} \mathrm{C}$ for 1 week, serially sectioned on a vibratome $(50 \mu \mathrm{m}$, horizontal plane), counterstained with $50 \mathrm{~nm}$ DAPI for $30 \mathrm{~min}$, and coverslipped with a DABCObased mounting media. Sections were visualized at high magnification and the position of individual labeled somata plotted on a cameral lucida outline of the glomerular layer in each section. The dorsoventral ( $z$-axis) of each cell was measured from the section number, and the rostrocaudal $(x$-axis) and the mediolateral ( $y$-axis) coordinates automatically measured in the camera lucida reconstruction using the Image Processing Toolkit (Reindeer Graphics).

Whole-cell recording. TH-GFP mice (6-8 weeks old) were anesthetized with saturated isoflurane vapor, decapitated, the olfactory bulbs surgically removed and immediately placed in $4^{\circ} \mathrm{C}$ oxygenated sucroseenriched artificial CSF [sucrose-ACSF; containing (in mM) $26 \mathrm{NaH}_{2} \mathrm{PO}_{4}$, $1 \mathrm{NaH}_{2} \mathrm{PO}_{4}, 3 \mathrm{KCl}, 5 \mathrm{MgSO}_{4}, 0.5 \mathrm{CaCl}_{2}, 10$ glucose, and 248 sucrose, $\mathrm{pH}$ 7.38 , saturated with $95 \% \mathrm{O}_{2} / 5 \% \mathrm{CO}_{2}$ ]. Horizontal slices ( $400 \mu \mathrm{m}$ thick) were cut using a Leica VT 1000 vibratome as previously described (Heyward et al., 2001). The slices were incubated in oxygenated ACSF 
[solution containing (in $\mathrm{mm}$ ) $124 \mathrm{NaCl}, 26 \mathrm{NaHCO}_{3}, 3 \mathrm{KCl}, 1.25$ $\mathrm{NaH}_{2} \mathrm{PO}_{4}, 2 \mathrm{MgSO}_{4}, 2 \mathrm{CaCl}_{2}$, and 10 glucose, $\mathrm{pH} 7.38$, saturated with $95 \% \mathrm{O}_{2} / 5 \% \mathrm{CO}_{2}$ ] at $30^{\circ} \mathrm{C}$ for $30 \mathrm{~min}$ and stored in ACSF at room temperature before use. For recording, individual slices were transferred to a recording chamber and superfused with $2.5 \mathrm{ml} / \mathrm{min} 95 \% \mathrm{O}_{2} / 5 \% \mathrm{CO}_{2}$ saturated ACSF maintained at $30^{\circ} \mathrm{C}$. GFP-labeled cells in the glomerular layer were observed using an Olympus $40 \times$ (NA 0.75) water-immersion objective on a BX51W upright microscope equipped for epifluorescence and near-infrared differential interference contrast optics.

Whole-cell (current and voltage) patch-clamp recordings were performed as previously described (Heyward et al., 2001). Briefly, recording pipettes were made from thick-wall borosilicate glass (outer diameter of $1.5 \mathrm{~mm}$, Sutter Instrument) pulled on a Flaming-Brown puller (Sutter $\mathrm{P}-97$ ). The intracellular solution contained (in $\mathrm{mm}$ ) $114 \mathrm{~K}$-gluconate, $17.5 \mathrm{KCl}, 4 \mathrm{NaCl}, 4 \mathrm{MgCl}_{2}, 10$ HEPES, 0.2 EGTA, $3 \mathrm{Mg}_{2} \mathrm{ATP}, 0.3$ $\mathrm{Na}_{2} \mathrm{GTP}$, and $0.1 \%$ biocytin, $\mathrm{pH} 7.3$ adjusted with $\mathrm{KOH}$, osmolarity 270 $\mathrm{mOsm}$, final pipette tip resistance $6-8 \mathrm{M} \Omega$, and seal resistance routinely $>3 \mathrm{G} \Omega$. All data were acquired with pCLAMP 9 software interfaced with a MultiClamp 700A amplifier and digitized with a DigiData $1322 \mathrm{~A} / \mathrm{D}$ board (Molecular Devices), low-pass filtered on-line at $2 \mathrm{kHz}$ (voltage clamp, sampling rate $5 \mathrm{kHz}$ ) or $10 \mathrm{kHz}$ (current clamp, sampling rate 40 $\mathrm{kHz})$. Constant-current electrical stimulation (10-100 $\mu \mathrm{A}, 170 \mu \mathrm{s}$ duration, PG4000A Digital Stimulator and SIU91 stimulus isolator, Cygnus Technology) was applied with bipolar twisted pair stainless steel wires (50 $\mu \mathrm{m}$ diameter), which were insulated except at their trips. The stimulator electrode was positioned in the ON layer slightly anterior to the recording site.

Spontaneous activity was recorded from juxtaglomerular cells in voltage clamp with spontaneous EPSCs (sEPSCs) analyzed from 5 min recording epochs. sEPSCs were detected on the basis of amplitude and area having at least 3:1 signal-to-noise ratio measured in the Minianalysis software package (Synaptosoft). A burst, or barrage, of sEPSCs was defined as in our previous study (Hayar et al., 2004b; Shao et al., 2009) to be a minimum of 4 EPSCs separated by $<15 \mathrm{~ms}$ intervals. Clearly, as the spontaneous EPSC input frequency increases the probability of EPSCs occurring with this time interval pattern by random chance increases. This was calculated as in (Shao et al., 2009). Briefly, the probability $(P)$ of having $N$ events in an interval of $T$ (seconds) duration within a trace having an EPSC event rate of $Q(\mathrm{~Hz})$ is given by the Poisson probability formula:

$$
P=\frac{\exp ^{(Q \times T)} \times(Q \times T)^{N}}{N !}
$$

Solving this equation for $N=4$ EPSCs (summing also the possibilities of $N=5,6$, etc) with a maximum inter-EPSC interval of $15 \mathrm{~ms}$ yielded an expectation for the number of "bursts" that would be detected by random alignment of 4 or more EPSCs in the trace. Thus, to be considered significant, and a cell classified as receiving bursts, observed spontaneous bursts had to exceed random chance predictions by 2.5 SDs, i.e., $99 \%$ confidence.

Morphometry. Biocytin-filled cells were stained as previously described (Heyward et al., 2001). Briefly, slices were fixed in phosphatebuffered $4 \%$ paraformaldehyde at $4^{\circ} \mathrm{C}$ for $16 \mathrm{~h}$, and then stored at $4{ }^{\circ} \mathrm{C}$ in long-term protectant (30\% sucrose, $30 \%$ ethylene glycol, $1 \%$ polyvinylpyrrolidone in $0.1 \mathrm{~m}$ PBS) until use. Individual $400 \mu \mathrm{m}$ slices were embedded in $10 \%$ gelatin in PBS and serially resectioned at $50 \mu \mathrm{m}$ on a vibratome. The sections were sequentially incubated in $0.3 \% \mathrm{H}_{2} \mathrm{O}_{2}$ in 0.1 M Tris-buffered saline (TBS) for $30 \mathrm{~min}$, washed in TBS, avidin-biotin complex (ABC kit; Vector Laboratories) in TBS containing $0.3 \%$ Triton X-100 overnight, washed in TBS, reacted with nickel-intensified diaminobenzidine, and coverslipped with DPX. These staining cells were three-dimensionally reconstructed under a $100 \times$ (numerical aperture 1.32) oil-immersion objective using a computer-aided camera lucida system (Neurolucida version 8.0; MicroBrightField). Any severed processes were followed across all of the $50 \mu \mathrm{m}$ sections from each slice to make the final three-dimensional (3D) model of each cell. The sections were then de-coverslipped, restained with $0.5 \%$ neutral red for $2 \mathrm{~min}$, and coverslipped again with DPX. Glomerular outlines were reconstructed in 3D by demarcating the neuropil to neutral red-stained juxtaglomerular cell boundary at 3-6 focal planes per glomerulus. These volumes were reconstructed across different sections in cases where the glomerulus was cut in half. Each section was aligned in 3D space with the biocytin fill process reconstructions to make a final 3D cell and glomerular model. This two-step reconstruction ensured that biocytin cell processes were reconstructed without potentially obscuring counterstains present.

From these 3D reconstructions, a large number of morphometric parameters were derived within Neurolucida and the following key measures expanded on within the results: (1) the sum of all processes; (2) the linear projection distance of a cell's longest process from the soma; (3) number of branch points; (4) number of process terminal ends not counting any artificially cut endings at the top/bottom of the slice; (5) number of primary processes deriving from the soma; (6) number of glomeruli containing at least $6 \mu \mathrm{m}$ of cell process; (7) the percentage of a cell's processes present inside each contacted glomerulus; and (8) the number of branch points inside each glomerulus contacted by a cell.

All data were represented as mean \pm SEM. To compare difference in morphometric measurements among multiple groups, one-way ANOVA (ANOVA: Bonferroni multicomparison test) or multivariate tests GLMANOVA and MANOVA were performed (Number Cruncher Statistical System software version 2004).

\section{Results}

Based on their appearance in Golgi-stained material (Golgi, 1875; Ramón y Cajal, 1911; Pinching and Powell, 1971), JG cells have been classically grouped into three morphotypes: ET, SA, and PG cells. ST cells, which have lateral dendrites that extend into the external plexiform layer, where they synapse with granule cells (see above), are not considered juxtaglomerular cells in our scheme but rather, along with middle and deep tufted cells, as part of the external plexiform layer. JG cells express different neurochemical markers. The major chemotypes are defined by expression of GABA synthetic enzymes (GAD65 and GAD67), DA, calretinin, calbindin, neurocalcin, and various combinations of these molecules (Ribak et al., 1977; Kosaka et al., 1998; Toida et al., 1998, 2000; Briñón et al., 1999; Parrish-Aungst et al., 2007); and others (for review, see Shipley et al., 2004).

\section{Two GABAergic chemotypes}

We first investigated the degree of coexpression of GAD65, GAD67, and TH by immunostaining in GAD65-GFP, GAD67GFP, and TH-GFP mice. Immunostaining for TH in GAD67GFP mice showed that virtually all $(97.4 \pm 1.2 \%) \mathrm{TH}+$ cells coexpress GAD67 ( $n=4$ animals, $233 \mathrm{TH}+$ cells), with $18 \%$ also expressing GAD65 (Parrish-Aungst et al., 2007). This is consistent with previous observations that DA cells are GABAergic (Kosaka et al., 1985, 1995; Gall et al., 1987; Baker et al., 1988; Parrish-Aungst et al., 2007). This TH+GAD67+ chemotype forms $\sim 30 \%$ of all GAD $67+$ cells; in contrast, only $7 \%$ of GAD65 + cells express TH (Parrish-Aungst et al., 2007). Therefore, the GAD65+ and TH + chemotypes comprise predominantly nonoverlapping populations of JG cells. GAD65+ cells are purely GABAergic, and TH+GAD67+ cells are DA-GABAergic (Fig. 1A). How do these "chemotypes" relate to the three classical Golgi morphotypes?

\section{TH+ and GAD67+ JG cells form interglomerular connections}

Periglomerular and external tufted cells are typically depicted with dendrites ramifying within a single glomerulus, whereas short axon cells contact multiple glomeruli. Fewer than $10 \%$ of 


\section{A Molecular Identity of PG and SA Cells}

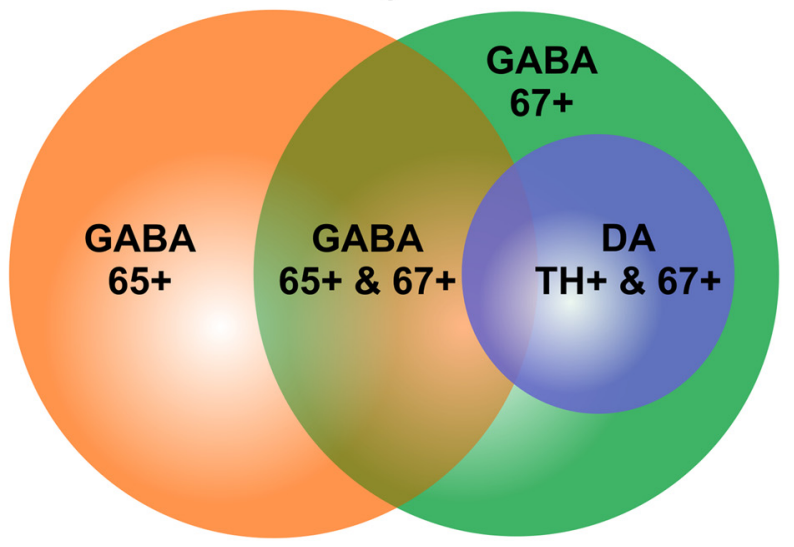

B

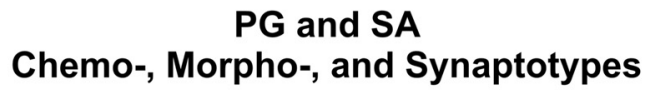

\section{Uniglomerular}

GABAergic (GAD65+)

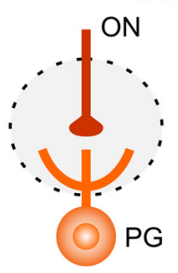

ONd $(30 \%)$

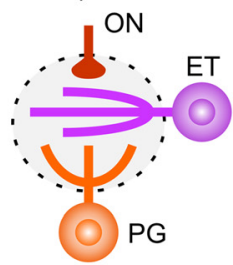

ETd $(70 \%)$

\section{Oligoglomerular}

DAergic/GABAergic (TH+/GAD67+)

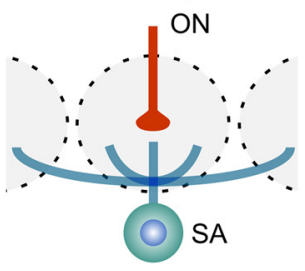

ONd $(30 \%)$

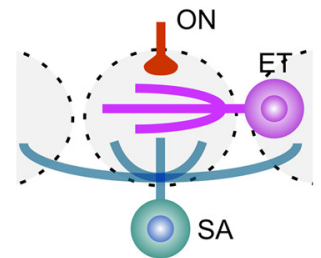

ETd $(70 \%)$
Polyglomerular DAergic/GABAergic (TH+/GAD67+)

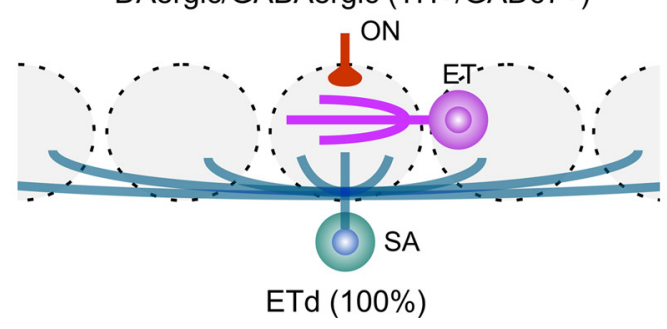

Figure 1. A, Venn diagram showing the heterogeneity in expression of GAD65, GAD67, and TH. Sphere area is proportional of the number of cells of each chemotype ( 300,000 GAD65+ cells, GAD67 + cells, and TH + cells). $B$, Schematic showing the relationship between different $\mathrm{PG} / \mathrm{SA}$ chemotype, morphotype, and synaptotypes. GABAergic (GAD65+) cells are functionally uniglomerular with $30 \%$ of cells receiving input via an $\mathrm{ON} \rightarrow \mathrm{PG}$ circuit $(0 \mathrm{Nd})$ and the remaining $70 \%$ via an $\mathrm{ON} \rightarrow \mathrm{ET} \rightarrow \mathrm{PG}$ circuit (ETd). DAergic/GABAergic (GAD67+) cells exhibit oligoglomerular (contacting up to 15 glomeruli) and polyglomerular (contacting upwards of 30 glomeruli) morphotypes. Oligoglomerular cells are similar to GAD65 + cells with $30 \%$ of cells receiving input via an $\mathrm{ON} \rightarrow \mathrm{PG}$ circuit and $70 \%$ via an $\mathrm{ON} \rightarrow \mathrm{ET} \rightarrow \mathrm{PG}$ circuit. All polyglomerular cells receive input via the $\mathrm{ON} \rightarrow \mathrm{ET} \rightarrow \mathrm{PG}$ circuit.
GABAergic (GAD65) neurons have interglomerular projections (Aungst et al., 2003). Here, we analyzed the interglomerular connections of TH+ and GAD67+ cells by retrograde labeling from discrete iontophoretic injection of FG into the glomerular layer of GAD67-GFP mice, and immunostaining the same material for TH (Fig. 2A-E). The vast majority of FG-labeled cells were confined to the glomerular layer. Only a small number of mitral/ tufted cells and some superficial granule cells immediately deep to the injection site were labeled, indicating minimal FG leakage into the EPL. Within the glomerular layer, labeling was heaviest near the injection site with the number of labeled cells gradually declining with increasing distance: $50 \%$ of labeled cells were at distances $>450 \mu \mathrm{m}$ and $10 \%$ at distances $>850 \mu \mathrm{m}(n=5$ animals; 5977 total cells counted) (Fig. $2 F$ ). This distribution is very similar to our previous study using DiI or fluorescent microspheres in which $50 \%$ of retrogradely labeled cells were at distances $>350 \mu \mathrm{m}$ and $10 \%>850 \mu \mathrm{m}$ (Aungst et al., 2003). The slightly greater distribution with FG may reflect greater diffusion of this tracer from the injection site or greater retrograde labeling efficiency compared to DiI or microspheres.

Near the injection site $(\leq 300 \mu \mathrm{m})$, FG-labeled cells contained TH and GAD67, GAD67 alone, or neither (FG only) (Fig. 2B-E). At greater distances, the proportion of labeled cells expressing $\mathrm{TH}$ or GAD67 increased to $\sim 90 \%$, while the number of retrogradely labeled cells containing FG only decreased to $\sim 10 \%$ at $1 \mathrm{~mm}$ (Fig. $2 G$ ). This indicates that a high percentage of interglomerular connections are formed by cells expressing TH and/or GAD67. This is consistent with a recent report that the majority of JG cells labeled at $500 \mu \mathrm{m}$ distance from a glomerular injection site express TH (Kosaka and Kosaka, 2008) and adds the finding that the vast majority of these TH cells coexpress GABA, specifically the GAD67 phenotype.

These findings also imply that TH+ GAD67+ and GAD65+ JG cells have markedly different morphology: TH+GAD67+ cells have axons and/or dendrites that contact many glomeruli, while GAD65+ JG cells have only short local processes.

\section{Synaptic inputs to DAergic JG neurons}

We next asked whether these chemotypes differ with respect to synaptic organization, i.e., synaptotype. Previous recordings made blind with respect to chemotype, indicated that all ET cells and $\sim 30 \%$ of PG cells receive monosynaptic ON input. All SA cells and $70 \%$ of PG cells receive indirect ON input mediated by ET cells (Hayar et al., 2004a). GAD65 + GABAergic PG cells form two populations (Shao et al., 2009): (1) ET-driven (ETd) PG cells, which comprise $\sim 70 \%$ of the GAD65 + PG cell population, receive spontaneous and ON-evoked bursts of EPSCs, and are driven primarily by a disynaptic $\mathrm{ON} \rightarrow \mathrm{ET} \rightarrow \mathrm{PG}$ circuit. (2) ON-driven (ONd) PG cells, comprising $\sim 30 \%$ of the GAD65 + PG cell population, do not receive spontaneous or ON-evoked bursts of EPSCs and are driven by monosynaptic ON input (Fig. $1 B$, top). Here, we examined the synaptic inputs of TH + GAD67 + cells in a line of mice in which the TH promoter drives expression of GFP.

Whole-cell recordings and biocytin fills were obtained from $>100$ TH-GFP-positive cells. Spontaneous EPSCs were analyzed from 46 randomly selected TH-GFP cells: 70\% (32 of 46) received recurring bursts of sEPSCs as well as isolated, single sEPSCs (Fig. $3 A, B$ ). The remaining 30\% (14 of 46) did not exhibit bursts of sEPSCs. Overall, TH-GFP "burst" sEPSC cells received $12.6 \pm 1.7$ sEPSCs/s and "single" sEPSC cells received $4.0 \pm 0.5 \mathrm{sEPSCs} / \mathrm{s}$. These sEPSC frequencies were statistically indistinguishable from those previously reported for GAD65 + cells, as was the $70-30 \%$ 

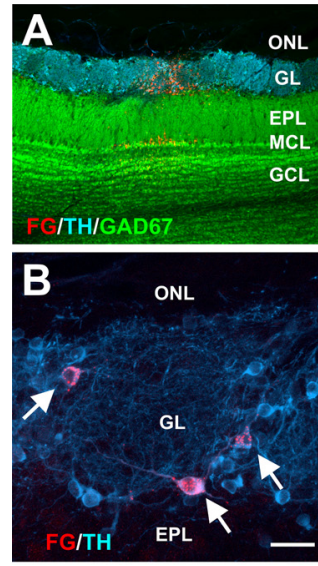

$\mathbf{F}$
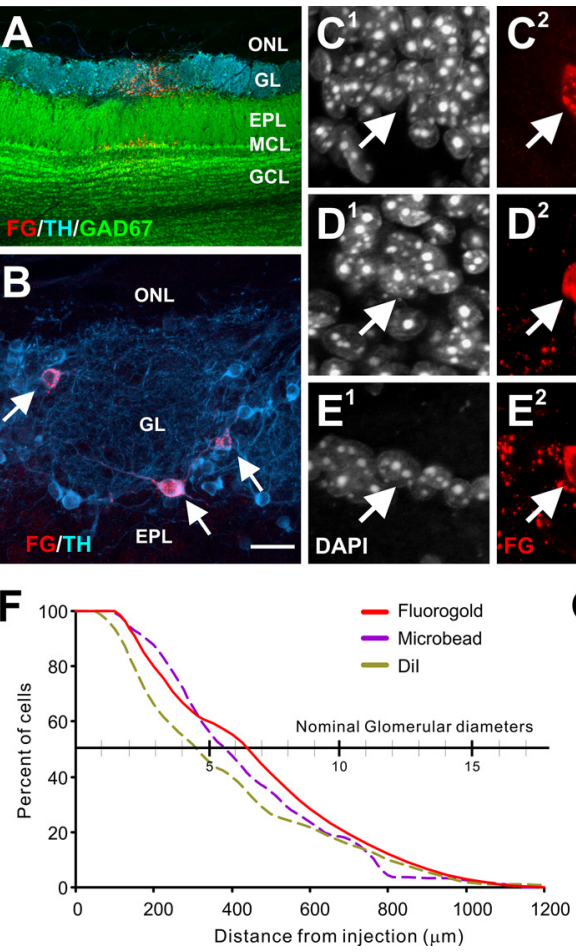
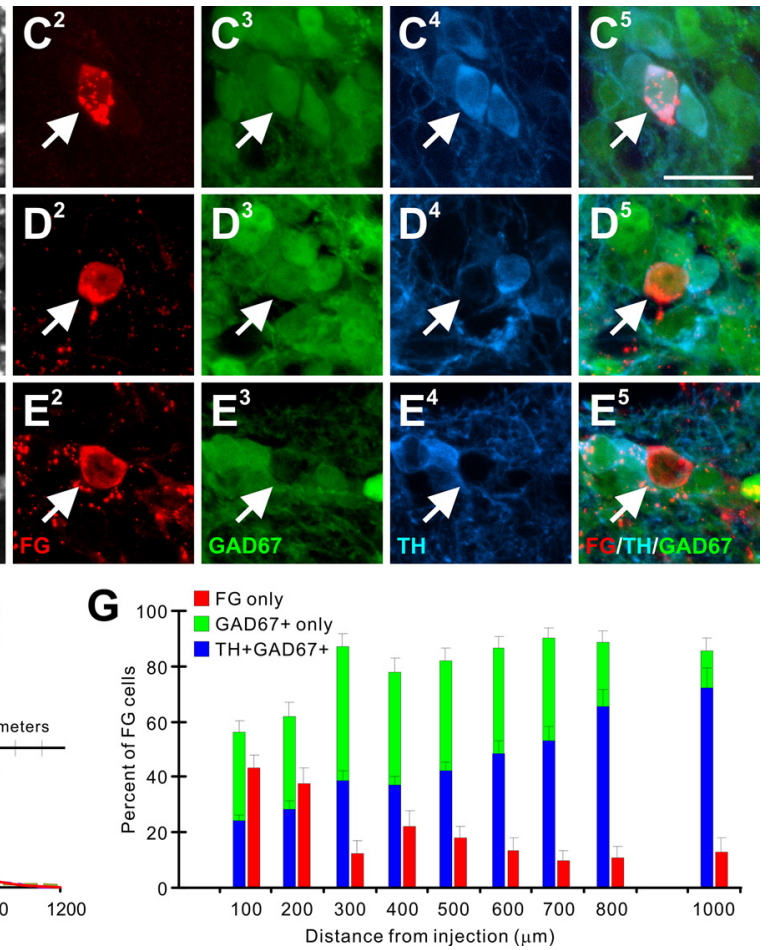

Figure 2. Retrograde labeling of interglomerular neurons. $\boldsymbol{A}$, Fluorogold-labeled cells (red) at a glomerular injection site in a GAD67-GFP (green) transgenic mouse, immunostained for TH (blue). A small number of mitral cells located below the injection site are labeled. $\boldsymbol{B}$, FG-labeled (red) and TH-labeled (blue) juxtaglomerular neurons (arrows) $500 \mu \boldsymbol{m}$ distant to a glomerular injection. $\boldsymbol{C}$, FG + cell within the glomerular layer $400-500 \mu \mathrm{m}$ distant to the FG injection site expressing GAD67 and TH ( $\boldsymbol{C}^{\mathbf{1}}$ shows DAPI nuclear stain, $\boldsymbol{C}^{2}$ shows FG, $\boldsymbol{C}^{\mathbf{3}}$ shows $\mathrm{GAD} 67-\mathrm{GFP}, \boldsymbol{C}^{4}$ shows TH, and $^{\mathbf{5}}$ shows triple overlay). D, FG + cell within the glomerular layer 400-500 $\mu \mathrm{m}$ distant to the injection site expressing GAD67 but not TH. $\boldsymbol{E}$, FG + cell within the glomerular layer $400-500 \mu m$ distant to the injection site negative for GAD67 and TH. $\boldsymbol{F}$, Percentage of FG-labeled cells plotted as a function of distance from the injection site. The distribution of labeled cells was not significantly different from previous Dil and microbead mouse glomerular injections (data from Aungst et al., 2003). G, Proportion of FG-labeled cells containing FG only, FG and TH/GAD67, or FG and GAD67 as a function of distance from the injection site. ONL, Olfactory nerve layer; $\mathrm{MCL}$, mitral cell layer; $\mathrm{GCL}$, granule cell layer. Scale bars: $\boldsymbol{A}$ (in $\boldsymbol{B}$ ), $20 \mu \mathrm{m} ; \boldsymbol{B}, 10 \mu \mathrm{m} ; \boldsymbol{C}-\boldsymbol{E}$ (in $\boldsymbol{C}$ ), $20 \mu \mathrm{m}$.

distribution of burst-sEPSC PG cells versus single-sEPSC cells (Shao et al., 2009). Thus, GAD65+ and TH+GAD67+ cells are indistinguishable in terms of patterns of spontaneous EPSCs.

Next we analyzed responses to ON stimulation. GAD65+ PG cells that receive spontaneous sEPSC bursts respond to ON stimulation with a burst of EPSCs, whereas single-sEPSC cells do not receive ON-evoked bursts of EPSCs (Shao et al., 2009). To investigate whether $\mathrm{TH}+\mathrm{GAD} 67+$ cells exhibit similar patterns of synaptic input, we analyzed responses to ON stimulation in 34 burst sEPSC and 31 single sEPSC TH+ cells. We used the minimum effective stimulus intensity (MES) necessary to elicit EPSCs in $\geq 95 \%$ of trials. The MES for single-sEPSC $(47 \pm 6 \mu \mathrm{A})$ and burst-sEPSC $\mathrm{TH}+$ cells $(57 \pm 5 \mu \mathrm{A})$ did not differ significantly. ON stimulation evoked bursts of EPSCs in all burst-sEPSC TH+ cells (mean $4.75 \pm 0.3 \mathrm{EPSC} /$ stimulation) and never evoked bursts in single sEPSC cells ( $1.5 \pm 0.1$ EPSCs/stimulation) (Fig. $3 C, D)$. Thus, as was the case for the GAD65 + PG chemotype, the patterns of spontaneous synaptic input predict the ON-evoked responses in the $\mathrm{TH}+\mathrm{GAD} 67+$ chemotype.

In GAD65 + cells, the latency and "jitter" (SD of latency) for ON-evoked EPSCs are correlated with spontaneous input patterns (Shao et al., 2009). TH+GAD67 + cells with spontaneous and ON-evoked single EPSCs had significantly lower latency and jitter (latency $2.65 \pm 0.1 \mathrm{~ms}$, range 1.6-3.8 ms; and jitter $185 \pm 10$ $\mu \mathrm{s}$, range 96-337 $\mu \mathrm{s}$ ) (Fig. $3 E, F$ ) than those with spontaneous and ON-evoked EPSC bursts (latency $4.77 \pm 0.21 \mathrm{~ms}, p<$ 0.000001 , range $2.7-8.9 \mathrm{~ms}$; and jitter $933 \pm 85 \mu \mathrm{s}, p<0.000001$; range $194-2454 \mu \mathrm{s}$ ) (Fig. $3 E, F$ ). Latency and jitter measures for single and burst-sEPSC $\mathrm{TH}+$ cells were statistically indistin- guishable from the counterpart populations of GAD65 + single/ $\mathrm{ONd}$ and burst/ETd cells, respectively [ONd: latency $2.63 \pm 0.06$ ms; jitter $173 \pm 9 \mu \mathrm{s}$; and ETd: latency $4.62 \pm 0.3 \mathrm{~ms}$; jitter $774 \pm$ $119 \mu$ s; reported by Shao et al. (2009)].

Recapping, these data show that, similar to GAD65 + PG cells, $\mathrm{TH}+\mathrm{GAD} 67+\mathrm{JG}$ cells participate in one of two distinct circuits (Fig. 1B): (1) Approximately 30\% lack bursts of sEPSCs and respond to ON stimulation with single EPSCs of short, relatively invariant latency. These properties are indistinguishable from ONd-GAD65 + PG cells indicating that $30 \%$ of DA-GABAergic JG cells are engaged in an $\mathrm{ON} \rightarrow \mathrm{PG}$ circuit. (2) The remaining $\sim 70 \%$ of $\mathrm{TH}+\mathrm{GAD} 67+$ cells receive bursts of sEPSCs and respond to $\mathrm{ON}$ stimulation with longer, more variable latency EPSC bursts. This synaptic profile is indistinguishable from GAD65 + ETd PG cells indicating that they are engaged in the $\mathrm{ON} \rightarrow \mathrm{ET} \rightarrow \mathrm{PG} / \mathrm{SA}$ cell circuit.

\section{GAD65 + and TH+GAD67+ cells have different morphotypes}

The physiological data indicate that the GAD65+ cells and $\mathrm{TH}+\mathrm{GAD} 67+$ cells have similar synaptic profiles, with equivalent proportions of each chemotype engaged in $\mathrm{ON}$-driven versus ET-driven glomerular circuitry. However, the retrograde tracing data presented above suggests that, at the population level, GAD65+ neurons have only short intraglomerular processes, whereas $\mathrm{TH}+\mathrm{GAD} 67+$ neurons have longer interglomerular connections. The results also imply that some GAD67+ (TH-negative) cells must have interglomerular connections, because the retrograde tracer ex- 
A Single sEPSC
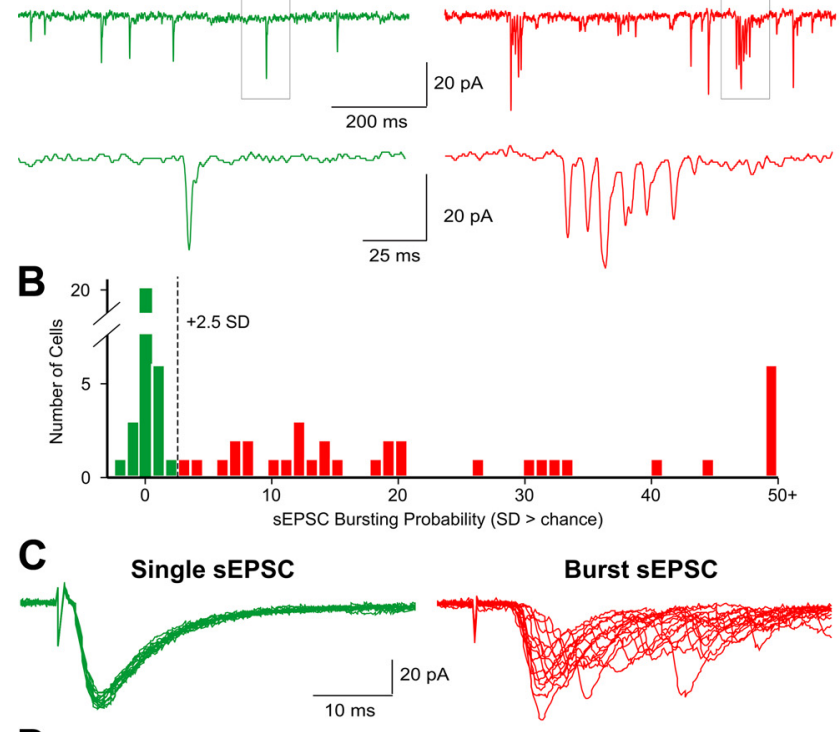

D
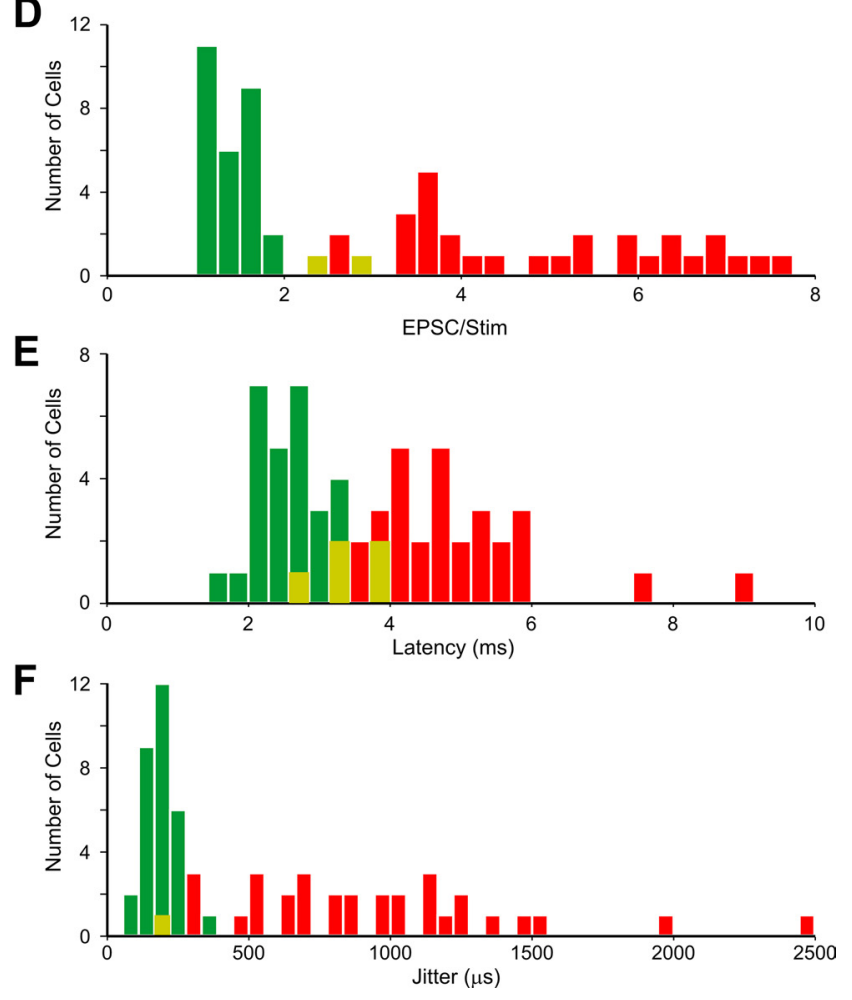

Figure 3. TH + cells differ in their sEPSCs and ON-evoked EPSC inputs. A, TH + GAD67+ cells exhibit single sEPSCS (left traces, green, $\sim 33 \%$ of cells) or bursts of sEPSCs (right traces, red, $\sim 67 \%$ of cells). The lower trace is an expansion of the EPSCs in the boxed region. $\boldsymbol{B}$, Histogram of the probability of sEPSC bursting for $65 \mathrm{TH}+\mathrm{GAD} 67+$ cells (abscissa). Bursting cells are defined as observed sEPSC bursts exceeding chance by $\geq 2.5$ SDs (dashed line; see Materials and Methods; single-sEPSC cells, green bars; burst-sEPSC cells, red bars). C, Superimposed traces of ON-evoked EPSCs in a single-EPSC cell (left trace, green, 15 sweeps) and a burst SEPSC cell (right trace, red, 15 sweeps). D, Histogram showing the number of EPSCs elicited by ON stimulation in 65 TH + GAD67 + cells. Regions of single- and burst-sEPSC cell overlap in the histogram are shown in yellow. $\boldsymbol{E}$, Histogram showing latency to ON-evoked EPSCS in burstSEPSC cells. Latency measured from the artifact generated by $0 \mathrm{~N}$ stimulation to the onset of the first evoked current evoked by minimum effective stimulation intensity. $\boldsymbol{F}$, Histogram showing the jitter in response to ON-evoked EPSCs in burst-sEPSC cells.
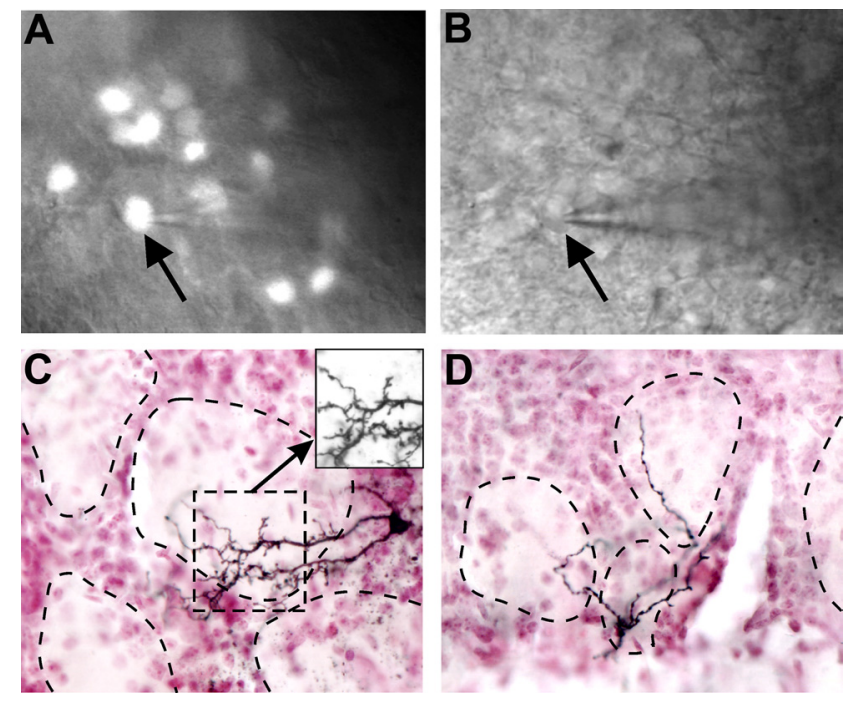

Figure 4. Biocytin filling of TH $+\mathrm{GAD} 67+$ cells in the glomerular layer. $A$, Neurons expressing GFP are easily visualized in the glomerular layer using an epifluorescent microscope. $\boldsymbol{B}$, The same cell is readily visible in DIC optics allowing whole-cell patch-clamp recording and biocytin filling of identified neurons (patch pipette attached to GFP + cell, arrow in $\boldsymbol{A}$ and $\boldsymbol{B}$ ). $\boldsymbol{C}, \boldsymbol{D}$, Biocytin-filled cell processes from two different cells stained with NiDAB and glomerular cellular boundaries visualized with neutral red staining. Inset, Biocytin-filled cell dendrites in the absence of neutral red staining. Dotted lines indicate outline of glomerular neuropil.

periments labeled cells that contained only GAD67 at distances $>500 \mu \mathrm{m}$ from the injection site (Fig. 3).

To investigate interglomerular connections at the level of individual neurons, we examined the morphologies of single, biocytin-filled, TH + GAD67 $+(n=30)$ and GAD65 $+(n=20)$ cells. Slices $(400 \mu \mathrm{m})$ containing filled cells were fixed, resectioned (50 $\mu \mathrm{m}$ ), stained with NiDAB (Fig. 4), and reconstructed in 3D using computer-aided camera lucida (Neurolucida software) (Figs. 5, 6). Unambiguous identification of axons versus dendrites was problematic, as many JG cells lack an axon as defined by electron microscopy (Price and Powell, 1970; Pinching and Powell, 1971). Moreover, PG cells can exhibit multiple thin dendrite branches that in light microscopy resemble axons. Thus, for quantitative purposes, we analyzed all biocytin-filled processes without attempting to distinguish dendrites from axons. All cells exhibited at least one spine. However, spines are highly labile, and their presence or absence may be altered in patchclamped neurons in slices; spine number was not quantified here.

$\mathrm{TH}+\mathrm{GAD} 67+$ and GAD65 + cell processes were always restricted to the glomerular layer. TH + GAD67+ cells have almost twice the total process length as GAD65 + cells $(1566 \pm 231 \mu \mathrm{m}$ for TH+ vs $803 \pm 92 \mu \mathrm{m}$ for GAD65 $+; p<0.05$ ) (Table 1) and more primary processes, i.e., those originating from the soma $(3.5 \pm 0.3$ for TH + vs $2.6 \pm 0.3$ for GAD65 $+; p<0.05)$. However, TH+GAD67+ neurons extend long processes through the GL, whereas the processes of GAD65+ neurons extend only a short distance from the soma. Indeed, only $50 \%$ of GAD $65+$ cells have a projection extending $>70 \mu \mathrm{m}$ and only $10 \%$ have a projection $>100 \mu \mathrm{m}$ (longest process $120 \mu \mathrm{m}$ ) (Fig. 5). In contrast, $50 \%$ of TH + GAD $67+$ cells have projections $>200 \mu \mathrm{m}$ and $10 \%$ $>650 \mu \mathrm{m}(\max 730 \mu \mathrm{m})$ (Fig. 6). These projection distances are shorter than the distances over which TH+GAD67+ cells were retrogradely labeled by FG. This is most likely due to the inevitable truncation of long processes in $400 \mu \mathrm{m}$ tissue slices. GABAergic and DAergic JG cells have generally been classified as PG cells 
A

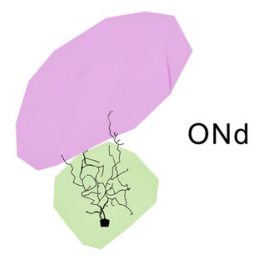

GABAergic (GAD65+) Uniglomerular

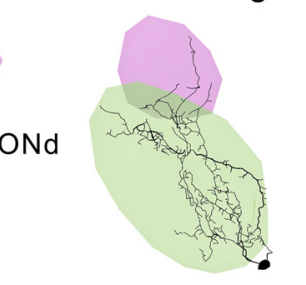

DAergic/GABAergic (GAD67+) Oligoglomerular
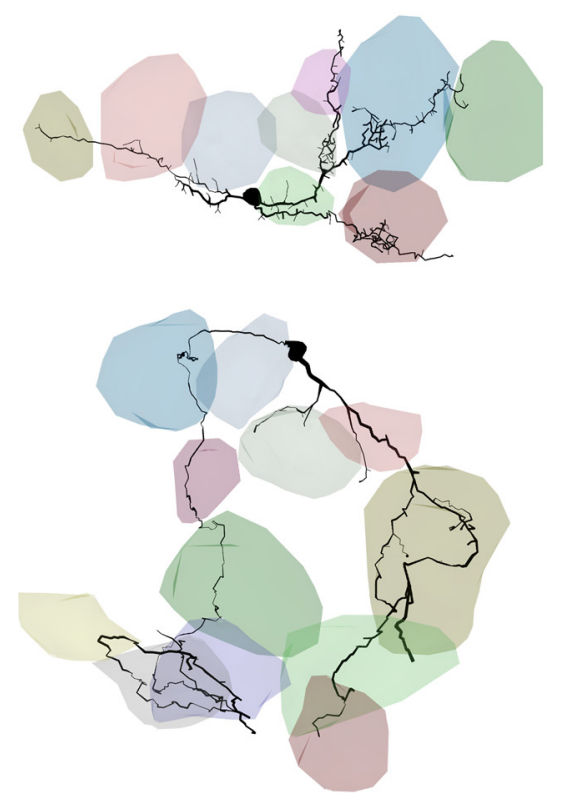

ONd
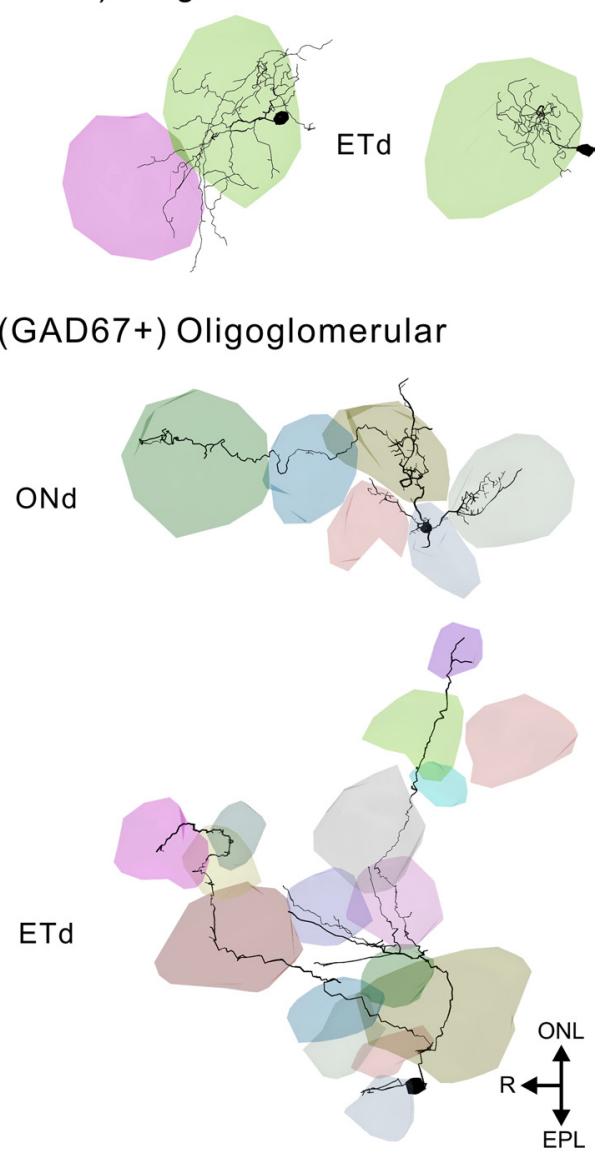

Figure 5. Three-dimensional reconstructions of biocytin-filled cells with individual glomeruli shown in different colors. A, GABAergic (GAD65 +) uniglomerular ONd and ETd cells. B, DAergic/GABAergic (GAD67+) oligoglomerular ONd and ETd cells. R, rostral. Scale bar, $100 \mu \mathrm{m}$.

with dendrites that ramify in a single glomerulus (Kosaka et al., 1985, 1995; Gall et al., 1987; Baker et al., 1988; Parrish-Aungst et al., 2007). Qualitatively, the biocytin-filled GAD65+ cells had such a compact dendritic tree, consistent with PG cell morphology. In contrast, both the retrograde tracing data, and singlecell 3D reconstructions, showed that the processes of TH+GAD67+ cells span distances encompassing multiple glomeruli.

To investigate the glomerular affiliations of GAD65+ versus $\mathrm{TH}+\mathrm{GAD} 67+$ chemotypes, we reconstructed the processes of our 50 biocytin-filled neurons relative to precise glomerular boundaries (Figs. 4, 5). We defined "innervated" as any glomerulus containing $>6 \mu \mathrm{m}$ of labeled processes. This cutoff, while arbitrary, was derived by estimating the maximum error in delineating glomerular boundaries at less than the diameter of a JG cell body ( $\sim 7 \mu \mathrm{m}$ soma in GAD65 + cells) (Parrish-Aungst et al., 2007). GAD65 + cells of both synaptotypes-ONd and ETd - contact a relatively small number of glomeruli $(2.5 \pm 0.3$ glomeruli/ cell for ONd and $2.3 \pm 0.3$ for ETd) (Table 1). In contrast, $\mathrm{TH}+\mathrm{GAD} 67+$ cells innervate significantly more glomeruli. ONd TH+GAD67+ cells contact $4.7 \pm 0.8$ glomeruli/cell and ETd TH+GAD67 + cells contacted $15.5 \pm 3.4$ glomeruli/cell (Table 1). However, the number of glomeruli contacted by ETd $\mathrm{TH}+\mathrm{GAD} 67+$ cells forms a distinct bimodal distribution: One population ( $15 / 20$ cells) innervates $7.5 \pm 0.9$ glomeruli; the second (5/20 cells) innervates $39.4 \pm 3.5$ glomeruli (Fig. $7 B)$.
Could this bimodal distribution be due to process truncation in the slices? Process truncation is inevitable, but random. Thus, if the underlying population of cells has a uniform morphology, truncation should produce a single, normal distribution in the number of contacted glomeruli, rather than the observed bimodal distribution. However, the 15 cells clustered at 7.5 glomeruli/cell fit one normal distribution, and the 5 cells in the 39.4 glomeruli/cell cluster fit a second normal distribution (Shapiro-Wilk and Anderson-Darling tests of normality), indicating that there are two distinct populations. We conclude there are two morphotypes of TH+GAD67+ cells, which we refer to as oligoglomerular-contacting a "few" glomeruli-and polyglomerularcontacting "many" glomeruli. In any distribution the majority of cases should fall within three SDs of the mean. Thus, the oligoglomerular DAergic-GABAergic morphotype should contact $<15-18$ glomeruli (3 SD above the mean for ONd and ETd cells) and the polyglomerular morphotype contact $>30$ glomeruli (3 SD below the mean).

While the number of glomeruli innervated provides some information about each cell's spatial extent (Table 1), the proportion of cellular processes within each innervated glomerulus may better reflect the number of synaptic contacts and hence the strength of a cell's functional interactions with a given glomerulus. To quantify the proportional glomerular innervation of GAD65 + and TH+GAD67+ cells, we analyzed the proportion of processes contained in each innervated glomerulus for each cell. Then, glomeruli were rank ordered for each cell, and population means were calculated for each chemotype and synaptotype (Fig. 7A).

For GAD65 + cells, 75-80\% of glomerular processes were contained within one primary glomerulus with only $10-25 \%$ in $1-2$ additional glomeruli (Fig. $8 A$ ). Further, $77 \pm 5.5 \%$ of process branch points were inside the primary glomerulus. There were no differences in the proportional innervation patterns of ONd and ETd GAD65 + cells. These quantitative measures strongly support the qualitative impression that GAD65 + GABAergic PG cells, regardless of patterns of synaptic input, can be considered uniglomerular.

Oligoglomerular ONd and ETd TH+ GAD67+ cells qualitatively appear to have more distributed processes. However, comparison of their proportional innervation patterns showed that ONd oligoglomerular cells have $50 \%$ of their glomerular processes within the first glomerulus, $22 \%$ in the second, $16 \%$ in the third glomerulus, and decreasing percentages in their remaining glomerular targets (Fig. 8 B, left). These cells have $56 \pm 8.4 \%$ of process branch points within the most highly innervated glomerulus. ETd oligoglomerular cells were similar, with $40 \%$ of glomerular processes within the first glomerulus, $22 \%$ in the second, $12 \%$ in the third glomerulus, and diminishing in their remaining glomeruli (Fig. $8 B$, right). ETd cells have $51 \pm 5.8 \%$ of branch 
points inside the first glomerulus. Thus, while oligoglomerular $\mathrm{TH}+$ cells do not have a distinct "principle glomerulus" in the same sense as GAD65+ cells, they do have a "preferred" glomerulus to which they contribute $40-50 \%$ of their processes. Oligoglomerular cells thus have connections with a limited number of neighboring, local glomeruli.

In contrast, polyglomerular cells with their long-range projections through the glomerular layer are fundamentally different. These cells have only $10 \%$ of their processes in their most highly innervated glomerulus with decreasing percentages throughout their remaining targets (Figs. 6, 8C). Thus polyglomerular DAGABAergic cells interact with sensory inputs and postsynaptic targets across dozens of glomeruli with approximately equal efficacy.

\section{Discussion}

Glomeruli are surrounded by juxtaglomerular interneurons that modulate input-output transformations of olfactory sensory information. JG neurons are heterogeneous with respect to chemotype (Ribak et al., 1977; Kosaka et al., 1998; Toida et al., 1998, 2000; Briñón et al., 1999; Parrish-Aungst et al., 2007), morphotype (Ramón y Cajal, 1911; Price and Powell, 1970; Pinching and Powell, 1971; White, 1972), and electrophysiological properties (Shepherd, 1963; Puopolo and Belluzzi, 1998; McQuiston and Katz, 2001; Hayar et al., 2004a; Shao et al., 2009). The view of glomeruli as static relay stations has given way to a more sophisticated picture in which multiple subtypes of JG cells form distinct intraglomerular and interglomerular circuits. These circuits generate intrinsic neural activity and dynamically regulate the transfer of information from olfactory sensory neurons to mitral/ tufted output neurons (Wachowiak and Shipley, 2006).

\section{DAergic-GABAergic neurons are short axon cells}

Historically, the terminology for cells within the glomerular layer first appeared as "neuroglia” by Golgi (1875), and in Kölliker's handbook of histology as "outer or superficial granule cells" (Kölliker, 1896). Blanes (1898) distinguished uniglomerular and biglomerular cells based on whether their dendrites enter one or several glomeruli. Blanes (1898) also described thin, difficult-tostain axons originating from biglomerular cells projecting exclusively within the glomerular layer. Blanes (1898) and Ramón y Cajal (1911) identified glomerular layer neurons as intraglomerular, or periglomerular, and external tufted. Pinching and Powell (1971) extended this terminology by defining a third glomerular layer cell type, the superficial short axon cell, described as having dendrites that are characteristically stout, branch infrequently; and axons that, when stained, are thin and short. Drawings of these cells show processes extending out to $\sim 150 \mu \mathrm{m}$ from the soma. Thus, historically there are three JG morphotypes: PG, ET, and SA cells.

GABAergic, DAergic, and most calcium-binding proteinexpressing juxtaglomerular neurons have been considered PG
DAergic/GABAergic (GAD67+) Polyglomerular
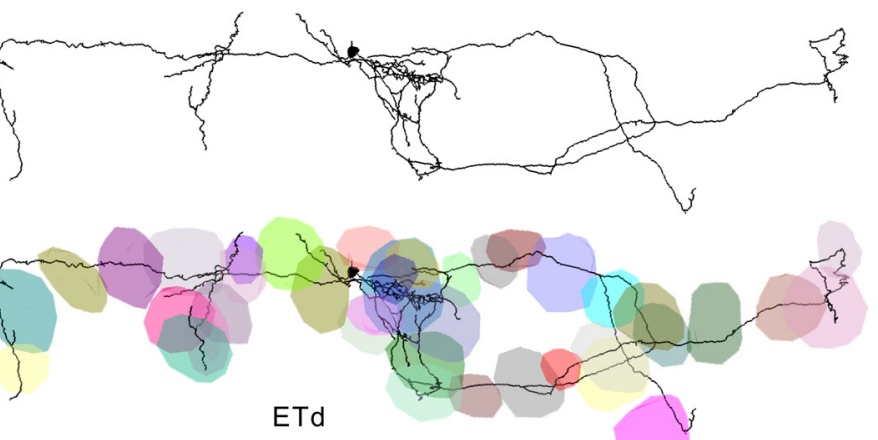

ETd
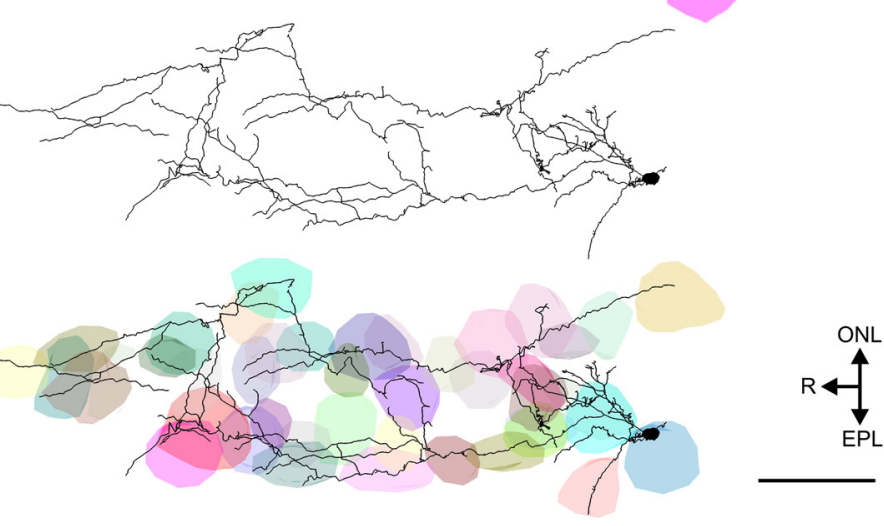

PL

Figure 6. Three-dimensional reconstructions of DAergic/GABAergic (GAD67+) polyglomerular cells with and without individual glomeruli shown in different colors. Scale bar, $100 \mu \mathrm{m}$.

cells (Kosaka et al., 1985, 1995; Gall et al., 1987; Baker et al., 1988; Parrish-Aungst et al., 2007). PG cells are generally depicted with dendrites ramifying within a single glomerulus, although the original descriptions of Kölliker (1896) and Blanes (1898) reported that dendrites can enter several glomeruli. The present findings demonstrate that GAD65 + GABAergic PG cells are essentially uniglomerular. These cells do contact an average of 2.3 glomeruli; however, the vast majority of their processes (75-80\%) ramify in a single principle glomerulus. Thus, GAD65 + cells fit the classical description of PG cells. TH+ neurons have traditionally been regarded as PG cells expressing dopamine and GABA. However, the present findings demonstrate that DAergic-GABAergic cells have a distinct morphotype, contacting multiple glomeruli. This does not fit the classical PG cell morphology, but rather, the morphology of SA cells (Pinching and Powell, 1971). DAergic JG cells have attracted significant attention, owing partly to their DAergic chemotype and observations that expression of TH is dependent upon olfactory sensory inputs (Baker et al., 1983). However, despite their prominence in the literature, DAergic JG cells comprise only $\sim 10 \%$ of juxtaglomerular neurons. Thus, while we recognize that reclassifying cells should never be undertaken lightly, our data indicate DAergic neurons are better considered short axon than periglomerular.

\section{Intraglomerular and interglomerular circuits}

GAD65 + GABAergic PG cells have a uniglomerular morphotype, but despite their relatively uniform morphology, they participate in two distinct functional circuits (Shao et al., 2009). Approximately $30 \%$ are driven by monosynaptic ON input (ON driven), receive little or no ET cell inputs, and contribute to $\mathrm{GABA}_{\mathrm{B}}$-dependent presynaptic feedback inhibition of their ON inputs. This $\mathrm{ON} \rightarrow \mathrm{PG}$ circuit may generate presynaptic and 
Table 1. Morphology of PG and SA cells

\begin{tabular}{|c|c|c|c|c|c|}
\hline \multirow{3}{*}{$\begin{array}{l}\text { Chemotype } \\
\text { Morphotype } \\
\text { Synaptotype }\end{array}$} & \multirow{2}{*}{\multicolumn{2}{|c|}{$\begin{array}{l}\text { PG cells } \\
\text { GABAergic (GAD65+) } \\
\text { Uniglomerular }\end{array}$}} & \multicolumn{3}{|c|}{$\begin{array}{l}\text { SA cells } \\
\text { DAergic/GABAergic (GAD67+) }\end{array}$} \\
\hline & & & \multicolumn{2}{|c|}{ Oligoglomerular } & \multirow{2}{*}{$\begin{array}{l}\text { Polyglomerular } \\
\text { ETd }\end{array}$} \\
\hline & ONd & ETd & ond & ETd & \\
\hline Number of cells $(n)$ & 10 & 10 & 10 & 15 & 5 \\
\hline Primary dendrites & $2.8 \pm 0.4$ & $2.4 \pm 0.4$ & $3.4 \pm 0.5$ & $3.3 \pm 0.4$ & $4.0 \pm 0.4$ \\
\hline Total processes $(\mu \mathrm{m})$ & $917 \pm 183$ & $722 \pm 97$ & $822 \pm 93$ & $1241 \pm 96$ & $4030 \pm 553$ \\
\hline Number of branch points & $39.1 \pm 8.5$ & $34.0 \pm 6.3$ & $34.1 \pm 4.8$ & $33.4 \pm 4.1$ & $76.6 \pm 11.0$ \\
\hline Number of terminal ends & $43.6 \pm 8.7$ & $38.2 \pm 6.5$ & $39.6 \pm 4.6$ & $39.4 \pm 4.1$ & $90.2 \pm 12.9$ \\
\hline Glomeruli innervated & $2.5 \pm 0.3$ & $2.3 \pm 0.3$ & $4.7 \pm 0.8$ & $7.5 \pm 0.9$ & $39.4 \pm 3.5$ \\
\hline
\end{tabular}
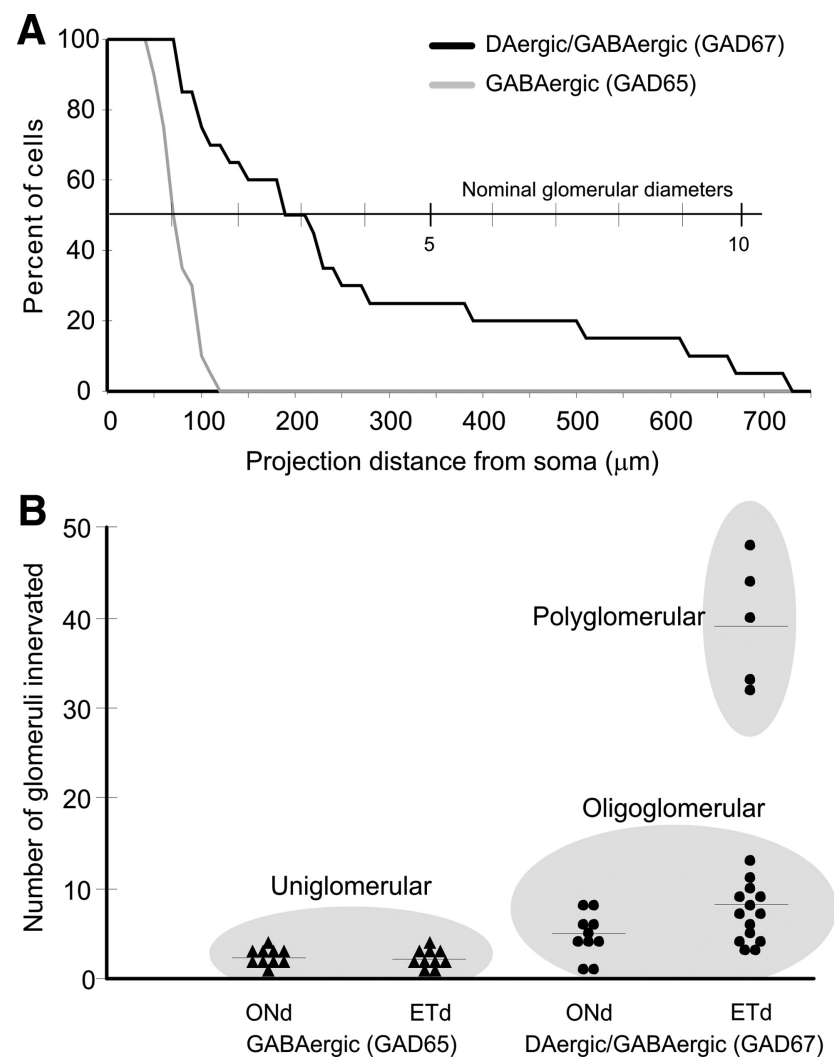

Figure 7. DAergic/GABAergic (GAD67+) neurons project greater distances and contact more glomeruli than GABAergic (GAD65+) cells. A, Percentage of biocytin-labeled GABAergic $($ GAD65 +) or DAergic/GABAergic (GAD67+) cells as a function of the projection distance of their most distal process from the soma. $\boldsymbol{B}$, Scatter plot showing the numbers of glomeruli contacted for each biocytin-filled cell. Uniglomerular, oligoglomerular, and polyglomerular groupings are indicated by the gray ellipses.

postsynaptic inhibition that is tightly linked to the instantaneous frequency of $\mathrm{ON}$ inputs. The remaining $70 \%$ receive their strongest drive from an $\mathrm{ON} \rightarrow \mathrm{ET} \rightarrow \mathrm{PG}$ circuit (ET-driven) with no or weak monosynaptic ON input. Since ET cells intrinsically burst, ET-driven PG/SA cells receive high levels of spontaneous input as well as ON-evoked phasic input. The high level of spontaneous drive to these ETd GABAergic PG cells results in sustained GABA release that causes significant tonic inhibition of $\mathrm{ON}$ terminals both in slices (Shao et al., 2009) and in vivo (Pírez and Wachowiak, 2008). Both circuits also contribute to postsynaptic inhibition.

The vast majority of the DAergic-GABAergic cells (25 of 30) had processes that span a relatively short region of glomerular layer linking 5-12 glomeruli. These oligoglomerular DAergicGABAergic cells are indistinguishable from GAD65+ GABAergic PG cells in terms of patterns of synaptic input: $30 \%$ are driven by monosynaptic ON input, and the remaining $70 \%$ receive their strongest drive from an $\mathrm{ON} \rightarrow \mathrm{ET} \rightarrow \mathrm{PG} / \mathrm{SA}$ circuit. Glomeruli activated by structurally similar odorants tend to occur in small groups or clusters, termed "modules" or "molecular feature clusters," that encompass 10-15 glomeruli (Johnson and Leon, 2000; Wachowiak and Cohen, 2001; Takahashi et al., 2004). Oligoglomerular DAergic-GABAergic cells span similarly sized glomerular regions and thus could function, in part, to coordinate signal processing in glomeruli responding to similar odorant features.

The second group of DAergic-GABAergic cells (5 of 30)polyglomerular cells- had much more extensive projections, directly contacting up to $\sim 50$ glomeruli. However, due to the inevitable truncation of such long processes in slice preparations, it is likely they contact many more glomeruli in vivo. Indeed, our retrograde tracing results indicate that DAergic-GABAergic cells are labeled at distances up to $1 \mathrm{~mm}$ from the injection site. If the processes from such cells extend equally in all directions, then polyglomerular DA cells could interact with hundreds of glomeruli. Polyglomerular DAergic-GABAergic cells were all ET-driven, i.e., they receive their strongest drive from the $\mathrm{ON} \rightarrow \mathrm{ET} \rightarrow$ PG/SA circuit.

Previous EM studies posited two PG cell morphotypes: type I receive $\mathrm{ON}$ and dendrodendritic synapses and type II receive only dendrodendritic synapses (Kosaka et al., 1997; Toida et al., 1998, 2000). GABAergic and DAergic cells were identified as type I and calbindin- and calretinin-positive cells as type II. ONd cells with direct $\mathrm{ON} \rightarrow \mathrm{PG}$ synaptotype likely correspond to type I cells. However, $\sim 70 \%$ of DAergic/GABAergic cells are ETd and receive their most effective inputs via the $\mathrm{ON} \rightarrow \mathrm{ET} \rightarrow \mathrm{PG} / \mathrm{SA}$ circuit, but many also receive weaker direct ON input (Shao et al., 2009). Thus, these might also have been classified as type I cells. Discrepancies between physiologically measured synaptic inputs and ultrastructural synapse counting are difficult to interpret, as there are multiple determinants of input efficacy, including number and cellular location of synapses, release probability, postsynaptic receptor types, and target cell intrinsic membrane properties.

\section{Functional implications}

ON terminals express $\mathrm{D}_{2}$ receptors (Palacios et al., 1981; Mansour et al., 1990; Nickell et al., 1991; Koster et al., 1999), and DA presynaptically inhibits ON inputs (Hsia et al., 1999; Berkowicz and Trombley, 2000; Ennis et al., 2001). In addition, both mitral/tufted cells and some unidentified JG neurons express DA receptors (Mansour et al., 1990; Coronas et al., 1997), but little is known about postsynaptic actions of DA on JG or MT cells.

Tyrosine hydroxylase expression is highly dependent on sensory input (Baker et al., 1983). Odor deprivation reduces TH immunoreactivity and olfactory bulb DA content (Baker et al., 1983, 1984); TH and DA are restored upon resumption of olfac- 
tory input (Cummings and Brunjes, 1997). Thus, olfactory experience, by altering DA synthesis, may modulate activity in the SA network. Long-term olfactory deprivation increases the proportion of MT cells that respond to a single odor, and the proportion of MT cells responding to more than one odor (Wilson and Sullivan, 1995). Interestingly, the $\mathrm{D}_{2}$ antagonist spiperone mimics the effects of deprivation on MT cell odor response patterns (Wilson and Sullivan, 1995), suggesting that decreased DA in the DAergic SA cell inhibitory network may unmask normally ineffective nerve inputs and increase MT cells receptive fields.

We previously described a long-range interglomerular circuit consisting of cells with similar morphology to the polyglomerular DAergic-GABAergic cells reported here (Aungst et al., 2003). Activation of the interglomerular circuit produces excitation of ET cells and inhibition of mitral cells. The inhibition of mitral cells was blocked by antagonists to either $\mathrm{GABA}_{\mathrm{A}}$ or AMPA/kainate receptors, indicating both glutamatergic and GABAergic linkages in this circuit. Based on these observations, we proposed that the interglomerular circuit comprised $\mathrm{SA} \rightarrow \mathrm{ET} \rightarrow \mathrm{PG} \rightarrow \mathrm{M} / \mathrm{T}$ cells and that the SA was excitatory. The present results, taken with a recent tract tracing study (Kosaka and Kosaka, 2008), show that short axon cells are DAergic-GABAergic. How can SA cells excite ET cells if the SA cell is DAergic-GABAergic? One possibility is that there is a small additional population of SA cells that are excitatory. This seems unlikely, as $\geq 90 \%$ of the neurons labeled distant to retrograde tracer injections expressed TH and/or GAD67, but it cannot be ruled out. Alternatively, ET cells may, paradoxically, be excited by inputs from DAergic-GABAergic SA cells. ET cells have a strong $I_{\mathrm{h}}$ current active near and below resting membrane potential (Liu and Shipley, 2008b). As a result of this current, IPSCs produce brief inhibition followed by a robust rebound excitation triggering a burst of action potentials (Liu and Shipley, 2008a). Indeed, activation of DAergic-GABAergic SA cells in the interglomerular circuit evokes transient inhibition followed by rebound spiking in ET cells, which in turn drives the GABAergic PG cells that inhibit MT cells (our unpublished observations).

The neurochemical identity of JG cells predicts the spatial extent of the glomerular networks in which they participate. These networks range from highly local intraglomerular circuits (GABAergic GAD65 + PG cells) to intermediate- and long-range interglomerular circuits (DAergic/GABAergic GAD67+ SA cells) (Fig. $1 B$ ). This diversity of intraglomerular and interglomerular microcircuits greatly enhances the capacity for spatiotemporal shaping of olfactory signals at the initial synaptic transfer in the olfactory pathway.

\section{GABAergic (GAD65+) Uniglomerular}

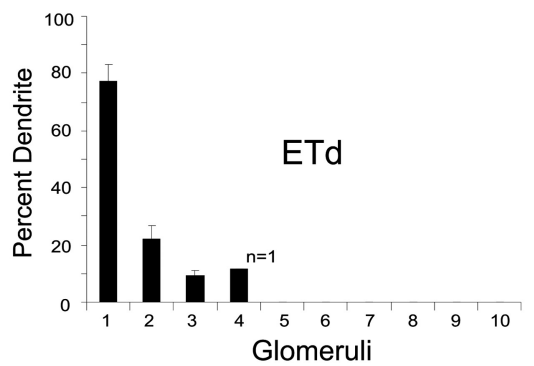

DAergic/GABAergic (GAD67+) Oligoglomerular

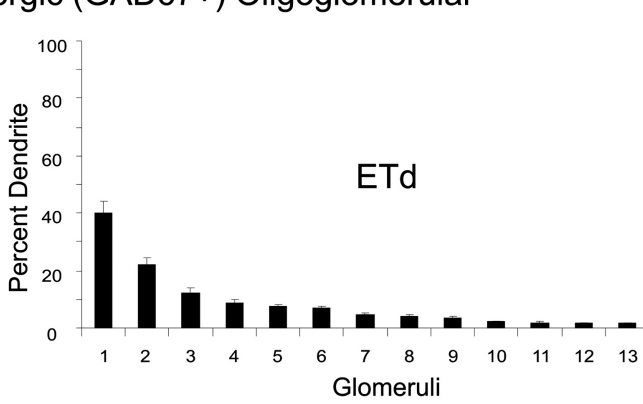

DAergic/GABAergic (GAD67+) Polyglomerular

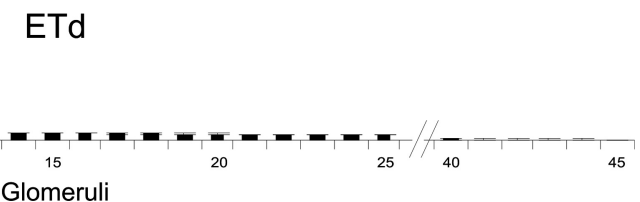

Glomeruli

Figure 8. Glomerular projections of GABAergic (GAD65+) and DAergic/GABAergic (GAD67+) cells. The percentage of proglomerulus. $A$, GABAergic (GAD65 +) ONd (left; $n=10$ ) and ETd (right; $n=10$ ) cells. B. DAergic/GABAergic (GAD67+) ONd (left; $n=10)$ and ETd (right; $n=10$ ) oligoglomerular cells. C, DAergic/GABAergic (GAD67+) ETd polyglomerular cells $(n=5)$.

\section{References}

Aungst JL, Heyward PM, Puche AC, Karnup SV, Hayar A, Szabo G, Shipley MT (2003) Centre-surround inhibition among olfactory bulb glomeruli. Nature 426:623-629.

Baker H, Kawano T, Margolis FL, Joh TH (1983) Transneuronal regulation of tyrosine hydroxylase expression in olfactory bulb of mouse and rat. J Neurosci 3:69-78.

Baker H, Kawano T, Albert V, Joh TH, Reis DJ, Margolis FL (1984) Olfactory bulb dopamine neurons survive deafferentation-induced loss of tyrosine hydroxylase. Neuroscience 11:605-615.

Baker H, Towle AC, Margolis FL (1988) Differential afferent regulation of dopaminergic and GABAergic neurons in the mouse main olfactory bulb. Brain Res 450:69-80.

Berkowicz DA, Trombley PQ (2000) Dopaminergic modulation at the olfactory nerve synapse. Brain Res 855:90-99.

Briñón JG, Martínez-Guijarro FJ, Bravo IG, Arévalo R, Crespo C, Okazaki K, Hidaka H, Aijón J, Alonso JR (1999) Coexpression of neurocalcin with other calcium-binding proteins in the rat main olfactory bulb. J Comp Neurol 407:404-414.

Chao TI, Kasa P, Wolff JR (1997) Distribution of astroglia in glomeruli of the rat main olfactory bulb: exclusion from the sensory subcompartment of neuropil. J Comp Neurol 388:191-210.

Coronas V, Srivastava LK, Liang JJ, Jourdan F, Moyse E (1997) Identification and localization of dopamine receptor subtypes in rat olfactory mucosa and bulb: a combined in situ hybridization and ligand binding radioautographic approach. J Chem Neuroanat 12:243-257. 
Cummings DM, Brunjes PC (1997) The effects of variable periods of functional deprivation on olfactory bulb development in rats. Exp Neurol 148:360-366.

Ennis M, Zhou FM, Ciombor KJ, Aroniadou-Anderjaska V, Hayar A, Borrelli E, Zimmer LA, Margolis F, Shipley MT (2001) Dopamine D2 receptormediated presynaptic inhibition of olfactory nerve terminals. J Neurophysiol 86:2986-2997.

Erlander MG, Tillakaratne NJ, Feldblum S, Patel N, Tobin AJ (1991) Two genes encode distinct glutamate decarboxylases. Neuron 7:91-100.

Gall CM, Hendry SH, Seroogy KB, Jones EG, Haycock JW (1987) Evidence for coexistence of GABA and dopamine in neurons of the rat olfactory bulb. J Comp Neurol 266:307-318.

Golgi C (1875) Sulla fina struttura dei bulbi olfactorii. Rome: ReggioEmilia.

Halász N, Ljungdahl A, Hökfelt T, Johansson O, Goldstein M, Park D, Biberfeld P (1977) Transmitter histochemistry of the rat olfactory bulb. I. Immunohistochemical localization of monoamine synthesizing enzymes. Support for intrabulbar, periglomerular dopamine neurons. Brain Res 126:455-474.

Halász N, Hökfelt T, Norman AW, Goldstein M (1985) Tyrosine hydroxylase and $28 \mathrm{~K}$-vitamin $\mathrm{D}$-dependent calcium binding protein are localized in different subpopulations of periglomerular cells of the rat olfactory bulb. Neurosci Lett 61:103-107.

Hayar A, Karnup S, Ennis M, Shipley MT (2004a) External tufted cells: a major excitatory element that coordinates glomerular activity. J Neurosci 24:6676-6685.

Hayar A, Karnup S, Shipley MT, Ennis M (2004b) Olfactory bulb glomeruli: external tufted cells intrinsically burst at theta frequency and are entrained by patterned olfactory input. J Neurosci 24:1190-1199.

Heyward P, Ennis M, Keller A, Shipley MT (2001) Membrane bistability in olfactory bulb mitral cells. J Neurosci 21:5311-5320.

Hsia AY, Vincent JD, Lledo PM (1999) Dopamine depresses synaptic inputs into the olfactory bulb. J Neurophysiol 82:1082-1085.

Johnson BA, Leon M (2000) Modular representations of odorants in the glomerular layer of the rat olfactory bulb and the effects of stimulus concentration. J Comp Neurol 422:496-509.

Kaneko K, Tamamaki N, Owada H, Kakizaki T, Kume N, Totsuka M, Yamamoto T, Yawo H, Yagi T, Obata K, Yanagawa Y (2008) Noradrenergic excitation of a subpopulation of GABAergic cells in the basolateral amygdala via both activation of nonselective cationic conductance and suppression of resting $\mathrm{K}+$ conductance: a study using glutamate decarboxylase 67 -green fluorescent protein knock-in mice. Neuroscience 157:781-797.

Kasowski HJ, Kim H, Greer CA (1999) Compartmental organization of the olfactory bulb glomerulus. J Comp Neurol 407:261-274.

Kölliker A (1896) Handbuch der Gewebelehre des Menschen, Vol 2. Leipzig, Germany: Verlag Von Wilhelm Engelmann.

Kosaka K, Hama K, Nagatsu I, Wu JY, Kosaka T (1988) Possible coexistence of amino acid (gamma-aminobutyric acid), amine (dopamine) and peptide (substance P); neurons containing immunoreactivities for glutamic acid decarboxylase, tyrosine hydroxylase and substance $\mathrm{P}$ in the hamster main olfactory bulb. Exp Brain Res 71:633-642.

Kosaka K, Aika Y, Toida K, Heizmann CW, Hunziker W, Jacobowitz DM, Nagatsu I, Streit P, Visser TJ, Kosaka T (1995) Chemically defined neuron groups and their subpopulations in the glomerular layer of the rat main olfactory bulb. Neurosci Res 23:73-88.

Kosaka K, Toida K, Margolis FL, Kosaka T (1997) Chemically defined neuron groups and their subpopulations in the glomerular layer of the rat main olfactory bulb-II. Prominent differences in the intraglomerular dendritic arborization and their relationship to olfactory nerve terminals. Neuroscience 76:775-786.

Kosaka K, Toida K, Aika Y, Kosaka T (1998) How simple is the organization of the olfactory glomerulus?: the heterogeneity of so-called periglomerular cells. Neurosci Res 30:101-110.

Kosaka T, Kosaka K (2008) Tyrosine hydroxylase-positive GABAergic juxtaglomerular neurons are the main source of the interglomerular connections in the mouse main olfactory bulb. Neurosci Res 60:349-354.

Kosaka T, Hataguchi Y, Hama K, Nagatsu I, Wu JY (1985) Coexistence of immunoreactivities for glutamate decarboxylase and tyrosine hydroxylase in some neurons in the periglomerular region of the rat main olfactory bulb: possible coexistence of gamma-aminobutyric acid (GABA) and dopamine. Brain Res 343:166-171.
Koster NL, Norman AB, Richtand NM, Nickell WT, Puche AC, Pixley SK, Shipley MT (1999) Olfactory receptor neurons express D2 dopamine receptors. J Comp Neurol 411:666-673.

Liu S, Shipley MT (2008a) Intrinsic conductances actively shape excitatory and inhibitory postsynaptic responses in olfactory bulb external tufted cells. J Neurosci 28:10311-10322.

Liu S, Shipley MT (2008b) Multiple conductances cooperatively regulate spontaneous bursting in mouse olfactory bulb external tufted cells. J Neurosci 28:1625-1639.

Liu WL, Shipley MT (1994) Intrabulbar associational system in the rat olfactory bulb comprises cholecystokinin-containing tufted cells that synapse onto the dendrites of GABAergic granule cells. J Comp Neurol 346:541-558.

Lodovichi C, Belluscio L, Katz LC (2003) Functional topography of connections linking mirror-symmetric maps in the mouse olfactory bulb. Neuron 38:265-276.

López-Bendito G, Sturgess K, Erdélyi F, Szabó G, Molnár Z, Paulsen O (2004) Preferential origin and layer destination of GAD65-GFP cortical interneurons. Cereb Cortex 14:1122-1133.

Macrides F, Schneider SP (1982) Laminar organization of mitral and tufted cells in the main olfactory bulb of the adult hamster. J Comp Neurol 208:419-430.

Mansour A, Meador-Woodruff JH, Bunzow JR, Civelli O, Akil H, Watson SJ (1990) Localization of dopamine $\mathrm{D}_{2}$ receptor mRNA and $\mathrm{D}_{1}$ and $\mathrm{D}_{2}$ receptor binding in the rat brain and pituitary: an in situ hybridizationreceptor autoradiographic analysis. J Neurosci 10:2587-2600.

Matsushita N, Okada H, Yasoshima Y, Takahashi K, Kiuchi K, Kobayashi K (2002) Dynamics of tyrosine hydroxylase promoter activity during midbrain dopaminergic neuron development. J Neurochem 82:295-304.

McLean JH, Shipley MT (1988) Postmitotic, postmigrational expression of tyrosine hydroxylase in olfactory bulb dopaminergic neurons. J Neurosci 8:3658-3669.

McQuiston AR, Katz LC (2001) Electrophysiology of interneurons in the glomerular layer of the rat olfactory bulb. J Neurophysiol 86:1899-1907.

Nickell WT, Norman AB, Wyatt LM, Shipley MT (1991) Olfactory bulb DA receptors may be located on terminals of the olfactory nerve. Neuroreport 2:9-12.

Palacios JM, Niehoff DL, Kuhar MJ (1981) [3H]Spiperone binding sites in brain: autoradiographic localization of multiple receptors. Brain Res 213:277-289.

Parrish-Aungst S, Shipley MT, Erdelyi F, Szabo G, Puche AC (2007) Quantitative analysis of neuronal diversity in the mouse olfactory bulb. J Comp Neurol 501:825-836.

Pinching AJ, Powell TP (1971) The neuron types of the glomerular layer of the olfactory bulb. J Cell Sci 9:305-345.

Pírez N, Wachowiak M (2008) In vivo modulation of sensory input to the olfactory bulb by tonic and activity-dependent presynaptic inhibition of receptor neurons. J Neurosci 28:6360-6371.

Price JL, Powell TP (1970) The mitral and short axon cells of the olfactory bulb. J Cell Sci 7:631-651.

Puopolo M, Belluzzi O (1998) Functional heterogeneity of periglomerular cells in the rat olfactory bulb. Eur J Neurosci 10:1073-1083.

Ramón y Cajal S (1911) Histologie du système nerveux de l'hommes et des vertébrés. Paris: Maloine.

Ribak CE, Vaughn JE, Saito K, Barber R, Roberts E (1977) Glutamate decarboxylase localization in neurons of the olfactory bulb. Brain Res 126:1-18.

Russ JC, Dehoff RT (1998) Practical stereology. New York: Plenum.

Sawamoto K, Nakao N, Kobayashi K, Matsushita N, Takahashi H, Kakishita K, Yamamoto A, Yoshizaki T, Terashima T, Murakami F, Itakura T, Okano H (2001) Visualization, direct isolation, and transplantation of midbrain dopaminergic neurons. Proc Natl Acad Sci U S A 98:6423-6428.

Schoenfeld TA, Marchand JE, Macrides F (1985) Topographic organization of tufted cell axonal projections in the hamster main olfactory bulb: an intrabulbar associational system. J Comp Neurol 235:503-518.

Shao Z, Puche AC, Kiyokage E, Szabo G, Shipley MT (2009) Two GABAergic intraglomerular circuits differentially regulate tonic and phasic presynaptic inhibition of olfactory nerve terminals. J Neurophysiol 101: $1988-2001$.

Shepherd GM (1963) Neuronal systems controlling mitral cell excitability. J Physiol 168:101-117. 
Shipley MT, Ennis M, Puche AC (2004) The olfactory system. In: The rat nervous system (Paxinos G, ed), pp 921-962. New York: Elsevier.

Takahashi YK, Kurosaki M, Hirono S, Mori K (2004) Topographic representation of odorant molecular features in the rat olfactory bulb. J Neurophysiol 92:2413-2427.

Tamamaki N, Yanagawa Y, Tomioka R, Miyazaki J, Obata K, Kaneko T (2003) Green fluorescent protein expression and colocalization with calretinin, parvalbumin, and somatostatin in the GAD67-GFP knock-in mouse. J Comp Neurol 467:60-79.

Toida K, Kosaka K, Heizmann CW, Kosaka T (1998) Chemically defined neuron groups and their subpopulations in the glomerular layer of the rat main olfactory bulb: III. Structural features of calbindin D28Kimmunoreactive neurons. J Comp Neurol 392:179-198.
Toida K, Kosaka K, Aika Y, Kosaka T (2000) Chemically defined neuron groups and their subpopulations in the glomerular layer of the rat main olfactory bulb-IV. Intraglomerular synapses of tyrosine hydroxylaseimmunoreactive neurons. Neuroscience 101:11-17.

Wachowiak M, Cohen LB (2001) Representation of odorants by receptor neuron input to the mouse olfactory bulb. Neuron 32:723-735.

Wachowiak M, Shipley MT (2006) Coding and synaptic processing of sensory information in the glomerular layer of the olfactory bulb. Semin Cell Dev Biol 17:411-423.

White EL (1972) Synaptic organization in the olfactory glomerulus of the mouse. Brain Res 37:69-80.

Wilson DA, Sullivan RM (1995) The D2 antagonist spiperone mimics the effects of olfactory deprivation on mitral/tufted cell odor response patterns. J Neurosci 15:5574-5581. 